\title{
Entre la guerra y el liberalismo: Aproximaciones a la independencia en Huamanga (1814-1824)
}

\author{
Nelson Pereyra \\ Universidad Nacional San Cristóbal de Huamanga \\ Recibido: 10-03-21 \\ Aprobado: 23-06-21 \\ doi: 10.46476/ra.v2i1.92
}

\section{Resumen}

El presente artículo plantea preguntas e hipótesis sobre los efectos de la independencia en Huamanga y las respuestas de los actores a través de las variables de guerra y liberalismo, que constituyen las dos caras de una misma moneda. En ese sentido, sostiene que la presencia de insurgentes, fuerzas libertadoras y españoles en la región y la difusión del liberalismo hispano, que proclamaba la libertad, la propiedad, la representación política y la ciudadanía, imprimieron el accionar de los campesinos mediante la conformación de partidas de guerrillas, las cuales apoyaron tanto a patriotas como a realistas. Estos guerrilleros empezaron a demandar los derechos y la ciudadanía que la Constitución de 1812 prometía, o a ejercer poder en la zona rural de Huamanga.

Palabras clave: independencia, campesinos, guerra, liberalismo, Huamanga. 


\section{Abstract}

This article raises questions and hypotheses about the effects of independence in Huamanga and the responses of the actors through the variables of war and liberalism; they are two sides of the same coin. It proposes that the presence of insurgents, liberating forces and Spaniards in the region and the spread of Hispanic liberalism, that proclaimed freedom, property, political representation and citizenship, influenced the actions of the peasants through the formation of guerrilla groups that supported both patriots and realists' forces. These guerrillas began to demand the rights and citizenship promised by the Constitution of 1812 , or to exercise power in the rural areas of Huamanga.

Key Words: Independence, peasants, war, liberalism, Huamanga.

\section{Resumo}

O presente artigo plante-a perguntas e hipóteses sobre os efeitos da independência em Huamanga e as respostas dos atores através das variáveis da guerra e do liberalismo, que constituem as duas faces da mesma moeda. Nesse sentido, sustenta que a presença de insurgentes, forças libertadoras e espanhóis na região e a difusão do liberalismo hispânico, que proclamava a liberdade, a propriedade, a representação política e a cidadania, influenciaram o acionar dos camponeses mediante a conformação de grupos de guerrilheiros, que apoiaram tanto patriotas como realistas. Estes guerrilheiros começaram a exigir os direitos e a cidadania prometidos pela Constituição de 1812, ou a exercer poder na zona rural de Huamanga.

Palavras-chave: independência, camponeses, guerra, liberalismo, Huamanga 


\section{Introducción}

La independencia es un tema recurrente en la historiografía peruana porque trasluce la separación política para con España y la formación de un Estadonación independiente y soberano. Existen varios trabajos que sintetizan el proceso y numerosos títulos que estudian sus diferentes aspectos y detalles. En la larga lista, destacan los textos sobre la guerra, las expediciones libertadoras, la respuesta del ejército realista y la participación de guerrillas y montoneras en el conflicto.

Es que la guerra decidió la independencia e influyó en la aparición y consolidación del Estado peruano. Años atrás, el sociólogo e historiador estadounidense Charles Tilly (1990) planteó que la guerra fue el motor de la formación del Estado moderno, pues le permitió administrar tierras, recursos y gentes; extraer excedentes para las acciones bélicas y organizar una infraestructura de tributación, abastecimiento y administración. A pesar de ser una teoría atractiva para el análisis de la formación de los Estados sudamericanos, ha sido descartada por algunos historiadores y sociólogos latinoamericanos, especialmente por Miguel Ángel Centeno, quien concluye que el esquema no se aplica a América Latina, porque aquí las guerras externas, como fuente de legitimación del Estado, desaparecen luego de la independencia (tomado de Méndez, 2013, p. 388).

Al contrario de Centeno, Cecilia Méndez ha recurrido a la teoría de Tilly, combinada con las propuestas del sociólogo Max Weber, para estudiar la relación entre el Estado y los campesinos peruanos en el contexto de las guerras caudillistas. Propone que en el siglo XIX, los campesinos no solo defendían al Estado, «sino que se constituían en Estado al asumir el ejercicio de la violencia que les delegaban los jefes militares en nombre del Estado» (Méndez, 2013: 386. El resaltado es de la autora). Agrega que en el contexto de las guerras civiles del siglo XIX, los campesinos apoyaban al ejército de varias formas y al mismo tiempo ejercían funciones de gobierno,

Aunque es común asociar a la guerra con el caos y la anarquía, los oficiales del ejército descansaron abrumadoramente en una población civil organizada [...] Las autoridades locales, además de cumplir un rol central en la formación de guerrillas, eran un nexo esencial en la logística del ejército y su avituallamiento. Soldados que llegaban a acampar, de lugares lejanos, por cientos y a veces miles, necesitaban lugares para dormir, provisiones y comida; sus caballos querían agua y forraje. Si no hubiera sido por una población organizada, ello no podría haberse obtenido. Estos patrones se replicarían después de la independencia (Méndez, 2013, p. 392. El resaltado es de la autora).

Las investigaciones de José Luis Igue (2008) también demuestran la formación de una estructura de poder en Pampa Cangallo, en la intendencia de Huamanga, que llegó 
a monopolizar el cobro del tributo en la etapa final de la guerra de la independencia. Por su parte, Gustavo Montoya (2019) describe la cultura política de las guerrillas y montoneras de la sierra central, aunque enfatiza el control político y militar que los oficiales patriotas y sus socios criollos ejercieron sobre ellas.

Sin embargo, la guerra por sí sola no pudo generar al Estado republicano; al contrario, necesitó de un acicate ideológico para empujar la formación de una estructura que ejerza poder a fin de concentrar y manejar recursos. Dicho estímulo fue el liberalismo proveniente de las cortes de Cádiz y de la Constitución de 1812, que proclamaba el origen popular de la soberanía y la vigencia de derechos como la propiedad, la libertad, la ciudadanía y el sufragio. El liberalismo estuvo vigente en la península ibérica en los dos interregnos liberales de 1812-1814 y 1820-1823. Como señala Nuria Sala, la guerra de la independencia coincidió con la aparición y reaparición del liberalismo hispano de las cortes de Cádiz, así como con la Constitución de 1812 y contribuyó a su difusión en un virreinato que se hallaba alterado por sublevaciones o por la presencia de las expediciones libertadoras. Al mismo tiempo, el liberalismo y la reacción absolutista de la monarquía española contribuyeron en la culminación de la guerra $(2011 ; 2012)$.

Conocemos bastante del liberalismo del congreso de 1822 y de ideólogos como Luna Pizarro o Sánchez Carrión, pero poco sabemos de la difusión de las ideas liberales entre los sectores populares. Nuevamente, Cecilia Méndez (2014) toma la delantera y esboza la tesis de la existencia de un liberalismo campesino en Huanta, durante la temprana república, especialmente en la guerra civil de 1834. Para épocas más tardías, Carmen McEvoy (1997) postula la aparición del liberalismo entre los artesanos de Lima que apoyaron a Manuel Pardo en 1872 y Nils Jacobsen y Nicanor Domínguez (2011) estudian el liberalismo de un personaje como Juan Bustamante, quien lideró la sublevación campesina de Huancané y Azángaro en 1866-1868.

Siguiendo estos avances, vale preguntarse por las características de la independencia en Huamanga, considerando que esta fue el resultado de guerra en una coyuntura de difusión de las ideas liberales. ¿Cómo se dio la relación entre guerra y liberalismo en la región y cómo reaccionaron los campesinos ante dicha relación?

Las siguientes líneas forman una sucinta aproximación a la historia de la independencia en la región de Huamanga (hoy Ayacucho) que, antes de enumerar conclusiones y certezas, plantean preguntas e hipótesis. A la par, constituyen una síntesis de algunos escritos que hemos elaborado en estos últimos tiempos y cuya publicación aún se halla pendiente. Siguiendo una línea de investigación inaugurada por la historiadora Nuria Sala, pretenden aproximarse a la historia de la emancipación a partir de las variables de la guerra y el liberalismo, que constituyen las dos caras de una moneda. 


\section{La intendencia de Huamanga}

El área de estudio es Huamanga, una región ubicada en los andes peruanos, que al iniciar el siglo XIX ocupaba un territorio de $44000 \mathrm{~km} 2$, dividido en seis provincias: Huanta, Huamanga, Cangallo, Lucanas, Parinacochas y Andahuaylas.

En los siglos XVI y XVII en el territorio de Huamanga se desarrolló una estructura económica caracterizada por la producción de obrajes, haciendas y talleres artesanales para la demanda de la mina de Huancavelica y dela ciudad de Huamanga, esta última sede de obispado desde 1602. Sin embargo, en la segunda mitad del siglo XVIII disminuyó la producción minera de Huancavelica, convirtiéndose la ciudad en la principal demandante de bienes agrícolas, ganaderos y manufacturas. Al mismo tiempo, los obrajes agonizaron por la contracción minera y la aparición de nuevos administradores de origen peninsular, que no pudieron enfrentar la mengua de la producción. El sistema de los repartos mercantiles, legalizado por la Corona en 1751, ocasionó una mayor importación de manufacturas. Con las reformas borbónicas, aumentaron imposiciones como la alcabala y la contribución indígena y se impusieron otras como el chepín (impuesto a la carne). Asimismo, las reformas exigieron el cumplimiento de la mita y el pago de las deudas de los indígenas (Pereyra, 2020, pp. 47-49).

Pese a la caída de Huancavelica y a la agonía de los obrajes, los chorrillos continuaron produciendo tejidos de tocuyo y bayeta para la demanda de la ciudad de Huamanga, de las ferias o de nuevos mercados como el de la sierra central o Lima. Según Jaime Urrutia, entre 1794 y 1810 se comercializaron más de 720.000 varas de tejido en mercados lejanos como Cerro de Pasco, Lima o Copiapó en Chile (1994, pp. 2226). En la década de 1810, el descenso de la explotación argentífera en Cerro de Pasco, la interrupción de los circuitos mercantiles y la importación de tejidos de Gran Bretaña ocasionaron la contracción de esta importante producción.

Otro de los bienes con alta demanda fue la coca, que se producía en las montañas de Huanta, Anco y Chungui. Según Hipólito Unanue, entre 1785 y 1789 en Huanta se producían 62.000 @ de coca y en Anco, $2.424 @$, todas destinadas a Huancavelica, a la ciudad de Huamanga, a las haciendas y a las ferias rurales (Sala, 2001, p. 28).

La agricultura y la ganadería fueron también actividades importantes al finalizar el siglo XVIII e iniciarse el XIX. Las cifras del diezmo nos aproximan a la producción agrícola de la intendencia, pese a que están incompletas debido a la reticencia de hacendados y campesinos para el pago de la obligación. De forma general, entre 1780 y 1785, las cifras revelan un repunte de la producción agrícola debido al poco impacto que la gran rebelión de Túpac Amaru tuvo en la región. Tras una caída al iniciarse el siglo XIX y entre 1814 y 1815 (el bienio de la sublevación del Cusco), la 
producción volvió a subir entre 1822 y 1823 (en plena guerra de la independencia) hasta alcanzar un cénit de 74.340 pesos, empezando luego a descender hacia fines de la década, debido a la sublevación de los campesinos altoandinos de Huanta en 1827. Lorenzo Huertas precisa que la caída de la producción agrícola a inicios de siglo y al finalizar la década de 1820 se acentuó en aquellas provincias que fueron afectadas por la guerra de la independencia, mientras que en las otras las fluctuaciones fueron moderadas (1982, pp. 222-230).

Precisamente, las fuerzas beligerantes se movieron y enfrentaron entre 1814 y 1824 en Huanta, Huamanga y Cangallo, lo que ocasionó la contracción de su producción agropecuaria. En 1826, el alcalde de la provincia de Huamanga comentó lo siguiente en una comunicación con el presidente o prefecto del departamento:

La cooperación de esta provincia y ciudad al triunfo de la libertad e independencia coronado al fin en sus mismos campos y como el atraso lamentable en que todos los ojos y con particularidad los observadores de Vuestra Excelencia ven la población de esta ciudad y provincia desaparecida en las filas libertadoras, al golpe de la venganza española, o por los desastres de la guerra, los edificios sagrados y profanos o derribados por tierra, o deteriorados o afeados, sin haber quien los restablezca o componga; las heredades abandonadas e incultas por falta de brazos o animales, herramientas y fondos con que laborearlos; los hatos de ganado yermos y solitarios; el comercio y una industria territorial en una decadencia que casi equivale a su nulidad total... 1

Las haciendas y demás unidades productivas de las tres provincias mencionadas también tuvieron problemas para comercializar su producción debido a la interrupción de los ejes mercantiles. El hacendado Antonio de Cárdenas señaló en 1820 lo siguiente:

Los funestos acontecimientos que pronostican las críticas circunstancias del tiempo [...] cuyo motivo y el de haber estado serrado por más de diez meses el paso general de Jauja y Guancayo por los disidentes siendo esos lugares del espendio [sic] con utilidad de la coca que produce dichos partidos [Anco y Chungui] en que a los interesados se les ha inferido gravísimos daños y perjuicios... ${ }^{2}$

El comercio de ganado entre Cangallo, Huamanga y la costa central fue interrumpido por la guerra. Aunque la crisis económica inició en esta zona tras las reformas borbónicas, el conflicto bélico agudizó la pobreza y ocasionó una movilidad social descendente, al punto que españoles y mestizos empobrecidos, que compartían la cultura e idioma de la población andina, fueron considerados como indígenas

1. Archivo Regional de Ayacucho (en adelante ARAy), Sección Municipalidad, leg. 70, oficios varios sueltos, 1826.

2. ARAy, Sección Municipalidad, leg. 46, alcaldía, oficios remitidos. 
(Igue, 2008, p. 30). Para enfrentar la crisis, un sector de los habitantes del lugar se dedicó al abigeato.

Con estos indicadores, algunos autores sugieren que la independencia en Huamanga es consecuencia de las reformas borbónicas, los repartos mercantiles y la crisis económica de inicios de siglo (Pozo, 1968; Huertas, 1972; Quichua, 2019). No obstante, no son los únicos factores a tomar en cuenta; al contrario, existen variables como el liberalismo y la misma guerra que deben de ser consideradas al analizar las respuestas de los actores sociales en un proceso tan complejo como el de la independencia. En las siguientes líneas analizaremos, precisamente, estas dos últimas variables.

\section{La guerra de la independencia en la región}

Entre 1814 y 1824, la región soportó la incursión de insurgentes, libertarios y realistas. La presencia de las fuerzas beligerantes en el territorio de Huamanga no solo ocasionó daños en la economía regional, sino movilizó a los grupos sociales y especialmente a los campesinos que formaron partidas de guerrillas.

Cuando en agosto de 1814 estalló la rebelión del Cusco, liderada por José Angulo y el curaca Mateo García Pumacahua, una fuerza militar fue enviada hacia Huamanga, bajo las órdenes de Manuel Hurtado de Mendoza, Gabriel Béjar y Mariano Angulo. En el trayecto, los rebeldes incrementaron sus tropas al contar con el respaldo de las comunidades ubicadas entre Andahuaylas y Huamanga. La fuerza militar ocupó la ciudad de Huamanga el 20 de septiembre de 1814 y luego se dirigió hacia el norte de la intendencia, para entablar batalla con las tropas realistas comandadas por Vicente González, que en Huanta fueron reforzadas con milicianos mestizos e indígenas.

Los rebeldes fueron derrotados primero en Huamanguilla, el 26 de septiembre de 1814 y luego en la misma villa de Huanta el 1 y 2 de octubre de 1814. Tras un repliegue hacia el este de la intendencia, fueron finalmente vencidos en el encuentro de Matará del 5 de febrero de 1815, por la superioridad numérica de los realistas. Y aunque unos cuantos siguieron resistiendo y hasta intentaron tomar la ciudad de Huamanga, la fuerza expedicionaria terminó diseminada debido a las fuertes contradicciones existentes en el grupo y al desánimo que causó la noticia de la derrota de Pumacahua en Umachiri.

Fracasada la rebelión, los realistas reprimieron con dureza a todos aquellos que apoyaron a los insurgentes. Por ejemplo, en Huanta los bienes del criollo Mariano Ruiz, quien se enroló en las tropas de Hurtado de Mendoza, fueron confiscadas y rematadas por el jefe español Nicolás Jerres. ${ }^{3} \mathrm{Y}$ en Ongoy (Andahuaylas), el

3. ARAy, Sección Juzgado de Primera Instancia, leg. 11, Causas Civiles, 1815, ff. 1v-3r. 
campesino Pedro José Landeo fue detenido y procesado cuando intentaba huir hacia Caravelí. ${ }^{4}$

La expedición del Cusco generó dos marcadas reacciones entre los campesinos de Huamanga: a favor y en contra. Las fuerzas rebeldes contaron con la adhesión de los pobladores de Cangallo, Pampa Cangallo, San Miguel, Tambo, Chiara, Socos, Vinchos, Acos Vinchos, Tambillo y Pischa. Asimismo, fueron secundadas por los alcaldes de indios del partido de Huamanga y mestizos «indianizados» que intervenían como intermediarios en la administración colonial. Al contrario, los realistas contaron con el apoyo de campesinos de Huanta, Luricocha, Huamanguilla, Quinua, Tambillo y Ñeque, quienes se encargaron de la contraofensiva y la represión (Pozo, 1968, p. 67; Huertas, 1972, p. 76; Sala, 1996, pp. 231-232, Igue 2008, pp. 2638). La misma situación volvió a ocurrir en 1820, cuando la Expedición Libertadora del Sur ocupó el territorio peruano.

Luego de desembarcar en Paracas y ocupar Pisco, San Martín envió a la sierra central una expedición al mando del general Antonio Álvarez de Arenales, con la intención de levantar a los pueblos y hostigar Lima. La expedición se encaminó hacia el este para traspasar la cordillera y llegar a Huamanga. En el trayecto, los expedicionarios se contactaron con los alcaldes de indios para reunir alimentos y provisiones para la tropa, comunicándoles quevenían para eliminar definitivamente la contribución indígena. El coronel argentino José Segundo Roca, quien integró las fuerzas de Arenales, señala en sus memorias que la expedición contó con el apoyo de la población campesina:

...los indios, las indias y todos los habitantes venían a ofrecer espontáneamente sus vaquitas, ovejas, papas, queso y cuanto tenía para mantención de nuestros soldados y hay que advertir que algunas de estas ofrendas y demostraciones las traían a cuestas habitantes de muy largas distancias, saludando a nuestros soldados con las palabras de patrianos, patriarcas, que sin duda creían sinónimos de patriotas y cuando nos acercábamos a pueblos grandes situados en eminencias elevadas que no era fácil llegar a nuestro camino, se contentaban con saludarnos al paso desde la cumbre de sus elevados cerros, con sus canciones tradicionales en quichua [sic] cantadas en coro por centenares de voces al son de sus flautas y tamboriles, que eran contestadas de nuestra parte batiendo al aire nuestros pañuelos (Roca, 1866, p. 28. El resaltado es del autor).

En su trayecto a Huamanga, la expedición reactivó las guerrillas que se habían formado en 1814 para apoyar a los rebeldes del Cusco. Con tan importante respaldo, llegó a la sede de la intendencia sin ser hostilizada por las tropas realistas. Luego de permanecer por más de diez días en Huamanga, continuó su recorrido por Huanta, Mayocc y Pampas hasta el valle del Mantaro. A inicios de diciembre

4. ARAy, Sección Intendencia, leg. 22, Causas Criminales, 186, f. 1 
alcanzó Cerro de Pasco, donde derrotó a las fuerzas realistas del brigadier Diego O'Reilly.

La presencia de Arenales en Huamanga y en la sierra central inquietó a los españoles. El virrey Pezuela envió tres batallones y dos escuadrones del ejército realista a Huamanga, a fin de reprimir las guerrillas. Las fuerzas realistas, bajo el mando de Mariano Ricafort, llegaron a la ciudad el 23 de noviembre de 1820 y al caer la noche se enfrentaron a los campesinos de Pampa Cangallo que apoyaban a los patriotas y se hallaban dispuestos a defender la villa. Luego de ocupar la ciudad, las tropas realistas se dirigieron a Cangallo a fin de reprimir a los campesinos en su misma base de operaciones. El 3 de diciembre los derrotaron en Chuspaconga y luego destruyeron el pueblo de Cangallo. A continuación, retornaron a la ciudad de Huamanga y en los siguientes meses consolidaron el control militar del territorio de la intendencia. Tras dejar en la ciudad una división al mando de José Carratalá, marcharon a Huancayo y Lima, siendo hostilizados por los guerrilleros de la sierra central.

Tal como sucedió en 1814, los españoles contaron con el concurso delos campesinos de Huanta, organizados en partidas de guerrillas, mientras que la expedición libertadora ganó principalmente el respaldo de los pobladores de Pampa Cangallo, tal como revela la siguiente comunicación entre Francisco Bermúdez, comandante de la división patriótica de libertos de Ica, y el gobernador Marcelo Granados:

Ricafort está en Huamanga solo con la fuerza de dos mil hombres no completos,
entre ellos muchos paisanos forzados, desarmados y últimamente se ha visto en
la necesidad de tomar para soldados hasta los colegiales. Por lo que respecta a
la marcha a ese destino, no sé qué se haya movido, y si se mueve, yo les picaré
la retaguardia. Todo lo que usted me anuncia del puente, y demás queda a mi
cuidado. Mi fuerza por ahora es de 800 a 900 hombres, que por todos los puntos
que vaya pienso hacer recluta. Los morochucos de Cangallo están sumamente
entusiasmados a nuestra labor y están haciendo una guerra terrible a los
enemigos...

Mientras tanto, San Martín trasladó su cuartel general a Huaura, al norte de Lima. Después de varios reveses que favorecieron a los patriotas, el nuevo virrey, José de La Serna, se entrevistó con el libertador. Tras el fracaso de la conferencia, abandonó Lima a inicios de julio de 1821, instalándose temporalmente en Huancayo para después moverse al Cusco. San Martín ingresó con su ejército a la capital para proclamar la independencia y asumir el mando político y militar bajo el título de protector del Perú.

5. Colección Documental de la Independencia del Perú (en adelante CDIP), Lima 1975, Tomo, V, Vol. $6^{\circ}$, p. 481. 
En la sierra central, el virrey consolidó su ubicación y ordenó a Carratalá intervenir en una zona como Huamanga, que era controlada por los guerrilleros, para reestablecer el enlace con el Cusco y todo el sur andino. Carratalá llegó a Huamanga en octubre de 1821 y lanzó una fuerte amenaza en contra de los pobladores de Cangallo. Los guerrilleros reaccionaron emboscando a la caballería realista en Secchapampa el 28 de noviembre, en una acción de encubrimiento que aprovechó el terreno pantanoso. En venganza, el jefe realista nuevamente incendió el pueblo de Cangallo; entonces, los guerrilleros lo sorprendieron en Chuschi y lo derrotaron el 18 de enero de 1822.

Mientras tanto, en Lima, la situación de los patriotas se deterioró rápidamente. Al estar empeñado en instalar un gobierno monárquico, San Martín descuidó la guerra, al extremo que los realistas ingresaron a la capital en septiembre de 1821 y permanecieron en el Real Felipe sin ser hostigados por el ejército libertador. Y el 7 de abril de 1822, las fuerzas combinadas de Domingo Tristán y Agustín Gamarra fueron derrotadas en la batalla de la Macacona, cerca de Ica, por Canterac y Valdés al intentar abrir una cuña entre las fuerzas realistas que estaban entre la sierra central, Cusco y Arequipa.

La derrota de La Macacona motivó a los realistas a escarmentar con dureza a los guerrilleros de Huamanga que habían establecido contacto con sus pares de Nazca y aún controlaban el territorio de la intendencia. Carratalá marchó hacia los partidos de Lucanas y Parinacochas e inició una dura represión. Luego, retornó a Cangallo y dirigió sus armas contra el líder guerrillero Cayetano Quirós, quien desde la costa central operaba sobre la cuenca del río Pampas, derrotándolo en el encuentro de Paras del 27 de abril de 1822. Conseguida la victoria, realizó importantes capturas de jefes guerrilleros como Basilio Auqui, Pedro Guaitalla, Pedro Yauta, Félix Mendoza, Manuel Corpus y Andrés Bautista y de alcaldes como el de Pomabamba, Juan Portillo, y el de Chuschi, Norverto Conde, quienes apoyaban a los patriotas. Con sus detenidos, retornó a la ciudad de Huamanga, donde capturó y fusiló a María Parado Bellido, quien informaba a los guerrilleros sobre el movimiento de las fuerzas realistas a través de la correspondencia que el jefe español encontró en las manos del alcalde Norverto Conde y de Félix Mendoza (Pereyra, 2018). A fines de mayo de 1822, los españoles recuperaron el control del territorio de la intendencia, pero ello fue temporal, pues dos años después las partidas nuevamente se reactivaron para la campaña final emprendida por Bolívar, que culminó con la célebre batalla de Ayacucho.

Efectivamente, en 1824 el ejército libertador de Sucre contó con el apoyo de pueblos como Huaychao, Acos Vinchos y Quinua, al marchar hacia la pampa de Ayacucho para el encuentro final con los realistas. Y tal como ocurrió diez años atrás, los españoles nuevamente fueron respaldados por los campesinos de Huanta y Huando (en Huancavelica), quienes incluso se levantaron contra los patriotas 
en noviembre del citado año, tal como se menciona en la siguiente comunicación entre Sucre y el ministro Sánchez Carrión:

El pueblo de Huanta no solo se ha sublevado contra las tropas libertadoras desde el 16 del mes pasado; sino que sus habitantes y los de todo su partido nos han hostilizado en todos sentidos. Han matado nuestros enfermos, han quitado las cargas que iban para el Ejército, han robado los equipajes, han cometido en fin toda especie de daños y últimamente presentaron una montonera de dos mil hombres para servir a los españoles. En virtud de las ordenes que Vuestra Señoría me da el 28 de noviembre respecto al Pueblo de Guando, he creído que Huanta deba castigarse muy severamente; pero aun cuando se le indulte por la capitulación del 9 de diciembre, no puede ser eximido de pagar los equipajes de los oficiales que robaron, particularmente cuando yo ofrecí a los oficiales reponerles sus equipajes si los perdían. Con este objeto he impuesto a Huanta una contribución de cincuenta mil pesos que deben sacársele por cualesquiera medidas que sean menester para realizarlo. ${ }^{6}$

En esta coyuntura, la guerra entre patriotas, guerrilleros y realistas se desenvolvió en medio de un liberalismo que proclamaba el origen popular de la soberanía y la vigencia de derechos como la propiedad, la libertad, la ciudadanía y el sufragio. A continuación, veremos las características del liberalismo en la región.

\section{El liberalismo en la independencia y en la formación del Estado republicano}

El liberalismo apareció en los inicios de la guerra por la independencia, en una coyuntura que ocasionó una gran transformación en la cultura política decimonónica. En efecto, germinó cuando las tropas francesas invadieron la península ibérica y depusieron al rey Fernando VII, imponiendo en su reemplazo al hermano de Napoleón Bonaparte. Los españoles no reconocieron al monarca usurpador e intentaron resolver el vacío de poder con la convocatoria a Cortes; estas se reunieron en 1810 en Cádiz y dieron la Constitución liberal de 1812, que transformó el absolutismo español en una monarquía constitucional y reconoció principios liberales como la soberanía, las elecciones para representantes, los derechos de libertad y propiedad y la ciudadanía para criollos, mestizos e indígenas.

El liberalismo postulaba el origen popular de la soberanía delegada a los representantes elegidos por el pueblo. Consideraba que ella provenía del pacto social entre individuos, cuya reunión constituía la comunidad de ciudadanos, fundada en el ejercicio de derechos políticos, como el derecho de sufragio (Chiaramonti, 2005, p. 353). Asimismo, defendía la libertad como una cualidad

6. CDIP, Lima 1975, Tomo V, Vol. 6º, p. 131. 
fundamental del derecho natural, de la que se desprendían otros derechos como la propiedad, la protección individual y la libertad de imprenta (Trazegnies, 1987, p. 113). Con respecto a la ciudadanía, las Cortes proclamaron a los indígenas como ciudadanos sin despojarles de sus privilegios y les ofrecieron una moratoria de 18 años para que aprendiesen a leer y escribir en español y los principios de la doctrina cristiana. ${ }^{7}$ Además, prohibieron los malos tratos hacia ellos y abolieron la pena de azotes, la mita, la contribución indígena, los repartimientos y los servicios personales a beneficio de particulares, curas y funcionarios. Igualmente, ordenaron la distribución de tierras a los indios casados o mayores de 25 años (Bernabéu, 2010, pp. 44-46). ${ }^{8}$

Además, el liberalismo español reparó la organización territorial, así como la administración regional y local del imperio. Suprimió el sistema de las intendencias y reconoció la existencia de provincias y pueblos. En reemplazo de los intendentes y de los antiguos cabildos, creó las figuras del jefe político superior, de la diputación provincial y de los ayuntamientos constitucionales. Estos últimos se hicieron cargo del gobierno de las poblaciones con 1.000 habitantes y de la administración de justicia. Los alcaldes electos fueron investidos como conciliadores con competencias en causas civiles o de injurias (Sala, 2011, pp. 696-699; 2012, pp. 426-429).

El liberalismo, emanado de las cortes de Cádiz y de la Constitución de 1812, tuvo vigencia en dos ocasiones: entre 1812 y 1814, cuando las tropas francesas retuvieron el control de la península ibérica hasta el retorno de Fernando VII al trono, y entre 1820 y 1823 , cuando el pronunciamiento del coronel Rafael del Riego obligó a la restauración de la Carta Magna y de las autoridades constitucionales en España y sus colonias. ${ }^{9}$ En el Perú, estas dos coyunturas coincidieron con la rebelión de los hermanos Angulo (1814-1815) y con la campaña final por la independencia (18201824). En la primera coyuntura, la Constitución fue reconocida en las ciudades y en los lugares más apartados del virreinato.

En la intendencia de Huamanga, la Constitución fue difundida y conocida entre 1812 y 1813. Fue públicamente jurada en la sede de la intendencia en 1812 y posteriormente en 1820. La primera jura, la de 1812, se realizó en un ambiente

7. El artículo $18^{\circ}$ de la Constitución de 1812 señala: «Son ciudadanos aquellos españoles que por ambas líneas traen su origen de los dominios españoles de ambos hemisferios, y están, avecindados en cualquier pueblo de los mismos dominios».

8. La Constitución negó la libertad a los esclavos y la ciudadanía a los negros y castos, aunque dejó la posibilidad de que las castas solicitasen a las Cortes su ciudadanía siempre y cuando cumpliesen servicios meritorios y reuniesen ciertos requisitos, ya que la ciudadanía «no venía gratuita» (O’Phelan, 2007, p. 275).

9. Entre 1814 y 1820, Fernando VII anuló la labor política y legislativa de las cortes de Cádiz, abolió la Constitución de 1812 y restableció la monarquía absolutista. Los liberales españoles intentaron oponerse a la restauración, o se exiliaron en Inglaterra. 
festivo, con la presencia de determinados símbolos relacionados con la monarquía española, como el busto del rey cautivo, Fernando VII. Contó con la participación de criollos, mestizos e indígenas, de los alcaldes y regidores del antiguo Cabildo colonial, de los alcaldes de indios, de los gremios, órdenes religiosas y población campesina. Después, la Carta Magna fue proclamada al menos en 135 pueblos de la intendencia (Méndez, 2014, p. 168).

La difusión de la Constitución en los pueblos de la intendencia encendió debates y motivó el reconocimiento de derechos y principios liberales. Estos sirvieron, por ejemplo, para que los campesinos de las alturas de Huanta, quienes reprimieron junto con los españoles a los insurgentes del Cusco, reclamen la posesión de las tierras de Culluchaca y Orccoguasi, que eran realengas pero usufructuadas por la comunidad. En 1814, el año de la rebelión de los hermanos Angulo, el alcalde indígena de Ccano, Félix Aguilar, demandó ante el juez de Huanta a Francisco Aguilar por intentar apropiarse de los citados predios:

Félix Aguilar, alcalde ordinario de naturales del pueblo de Ccano, en voz y nombre del común de mi cargo ante U como más haya lugar en derecho, digo que Francisco Aguilar, de casta español, pretende despojarnos de las tierras nombradas de Illicapata sobre que se ha seguido autos y están presentados recibos de los curacas antiguos, que entre yndios son equivalentes a títulos y respecto a que la nueva Constitución nacional previene que a los de nuestra naturaleza se les den tierras a proporción quando estas no las hubiésemos poseído de tiempo inmemorial, se nos debía adjudicar y devolverse al citado Aguilar lo que costaron en composición con el juez revisitador según lo prevenido por Real Cédula de su majestad. ${ }^{10}$

La cita expresa que el concepto de propiedad, asociado la vigencia de la Constitución de Cádiz, caló hondo entre los habitantes de pueblos como Culluchaca, Ccano o Uchuraccay. Como bien dice Cecilia Méndez, fueron los comerciantes y arrieros quienes introdujeron la Carta Magna en las alturas de Huanta. Con las ideas liberales, los campesinos de esta parte de la intendencia no solo defendieron las tierras consideradas como suyas, sino que forjaron un «liberalismo popular» con el que pactaron con caudillos como Orbegoso o Santa Cruz en las guerras tempranorepublicanas (Méndez, 2014).

Asimismo, el interregno liberal, en medio de la guerra, ocasionó la transferencia de recursos y poderes del gobierno virreinal a las provincias, ya que estas tuvieron que mover hombres y bienes para el conflicto. Antonio Annino señala que las autoridades de los cabildos de indios y de las comunidades se convirtieron en jefes militares, o se encargaron de administrar justicia, de tal forma que se inició

10. ARAy, Corte Superior de Justicia, leg. 36, Expedientes Civiles de Huanta, 1849, f. 61. 
un proceso de ruralización de lo político (2010, pp. 235-283). Precisamente, ello ocurrió con los campesinos de las alturas de Huanta y con los guerrilleros de Pampa Cangallo llamados morochucos.

Cecilia Méndez indica que el líder huantino José Antonio Guachaca enarboló las ideas liberales de la Constitución gaditana y rechazó el tributo indígena y el trabajo impago de los campesinos en 1813. Posteriormente, se alió con caudillos liberales como Orbegoso para defender el gobierno del golpe de Estado de 1834 dirigido por Bermúdez e ideado por Gamarra (2014, pp. 169-171). Bajo el mando de este líder carismático, los campesinos altoandinos de Huanta hostilizaron a las fuerzas libertadoras en la independencia (Husson, 1992, p. 67) y se levantaron en armas contra la joven República con el propósito de defender los derechos y estatus que habían adquirido en los últimos decenios de la dominación colonial. En el transcurso de su sublevación, rechazaron la contribución indígena y a las autoridades nominadas por el gobierno central (Bonilla, 1996, pp. 146-147). Fracasado el levantamiento, Guachaca ejerció el poder al instalar en su cuartel de Luis Pampa (Uchuraccay) un gobierno con el que cumplió funciones judiciales y administrativas; es decir, fundó una «República Plebeya» que subvertía la jerarquización social heredada de la colonia porque en ella los campesinos ocupaban la cúspide de la estructura de poder.

Asimismo, al enfrentar y contener exitosamente a los realistas entre $1820 \mathrm{y}$ 1821, los morochucos no solo controlaron militarmente un amplio territorio entre Huamanga, Cangallo, Lucanas y Parinacochas, sino que establecieron una estructura de poder al nominar a sus propias autoridades, cobrar los tributos e imponer cupos y multas, según las indagaciones de José Luis Igue. En julio de 1821, el subdelegado de Lucanas, José de Yrigoyen y Zenteno, señaló que los guerrilleros de Pampa Cangallo ingresaron a su partido «con el mayor descaro imponiendo Leyes de Gobierno y nombrando alcaldes de la Patria». Dijo que habían asesinado a los curas de Colca y Carhuanca y al de Tiquihua le habían impuesto una multa de mil pesos porque guardaba los «caudales del rey». Para concluir su acusación de naturaleza política, mencionó lo siguiente:

Con tales estragos han hido adrredrentando [sic] todos los lugares de este continente y ellos mostrándose aguerridos se abanzan a establecer leyes, dirigir proclamas seductibas, y espedir nombramientos de comandantes militares para que se interrumpa el pago de tributos y de las obenciones eclesiasticas, bajo de las penas arbitrarias a los contraventores. Estas determinaciones se han propagado en todo el territorio de mi mando y queriendo zelar aquellos barbaros su más puntual cumplimiento se dirigen a tropadas por todos los pueblos de este partido, alentando a los de su clase para emprender robos contra los vecinos acomodados y por conclusión hubieron de meditar fuese asaltada mi persona con la idea de conducirme preso a un lugar que llaman la Pampa, donde tienen hecho su 
campamento [...]. Enpedernidos en la culpa y con la confianza de no haver suficientes tropas en Guamanga para castigarlos, se consideran unos déspotas, árvitros de salirse con todo lo que apetecen [...] (tomado de Igue, 2008, p. 66. El resaltado es del autor).

Algunos de estos nombramientos subsistieron luego de la batalla de Ayacucho y fueron formalmente incorporados a la estructura política de un Estado que estaba en construcción. La autoridad de Guachaca, por ejemplo, fue reconocida por el presidente Orbegoso en 1834, puesto que los campesinos altoandinos de Huanta fueron sus socios estratégicos al enfrentar la revolución del general Pedro Bermúdez (Méndez, 2005). Pero el caso más paradigmático es el de Pedro José Gutiérrez, propietario de la estancia de Seccha, quien se desempeñó como juez de paz en Cangallo en 1820, cuando las tropas de Arenales ocuparon la intendencia y los pobladores de Pampa Cangallo reactivaron las guerrillas. Gutiérrez retuvo el cargo en el transcurso de la guerra porque pudo cubiletear entre españoles y morochucos o porque fue un guerrillero. Lo cierto es que el personaje continuó como juez en las décadas de 1830 y 1840 , actuando a nombre del Estado republicano. En 1845 le tocó resolver un caso de disputa de terrenos que enfrentó a los campesinos de Pomabamba con los de Urihuana, Huallchancca y Tucsín en Cangallo. En medio del proceso, fue cuestionado por los pobladores de Pomabamba por no ser imparcial. Los quejosos mencionaron lo siguiente:

Los colitigantes de Hualchanga se componen entre todos del número de catorce a quince individuos, pero el señor juez de paz (según la voz común) con título de coronel alarmó para la turbulencia la masa de los morochucos, como si nosotros hubiésemos solicitado la pelea. Ya habíamos estado instruidos desde antes de que los de Hualchanga, apoyados del influjo del juez, estaban escudados con la fuerza de morochucos para quitarnos nuestros terrenos y hacerse [dueños] absolutos de nuestras propiedades. ${ }^{11}$

Silaversión delos pomabambinoses cierta, entonces deducimosque el juez Gutiérrez fue un morochuco y como tal, ejerció el poder en un territorio anteriormente controlado por los guerrilleros. Al mediar en las disputas judiciales, se transformó en un actor clave para reproducir las normas y rituales del recientemente creado Estado republicano.

11. ARAy, Corte Superior de Justicia, Expedientes civiles de Huamanga, expediente 15, paquete 1, 1845, f. 13 . 


\section{Epílogo}

La historia de la independencia en Huamanga es un proceso complejo con muchas aristas y detalles. En la presente comunicación hemos intentado abordar un par de dichas aristas: la guerra y el liberalismo, dejando de lado un aspecto no menos importante como el rol de los otros actores sociales (españoles, criollos, mestizos, gremios, religiosos) o el manejo de recursos durante la guerra. Esbozar una historia total del impacto de la emancipación en la región es todavía una tarea pendiente, especialmente en el contexto actual conmemoratorio del bicentenario.

Tal como afirma Tilly, la guerra fue el motor para la formación del Estado republicano, pues ocasionó la formación de una estructura de poder para concentrar y manejar recursos. Pero la guerra, para formar un Estado, necesitó de una ideología que estimule y legitime el ejercicio del poder y la organización de hombres y recursos. Dicho estimulo provino del liberalismo doceañista que proclamaba la soberanía emanada del pueblo y derechos como la propiedad, la libertad, la ciudadanía y el sufragio.

Como hemos visto en las páginas anteriores, el liberalismo se difundió en el territorio de la intendencia de Huamanga, en dos coyunturas marcadas por la rebelión de los hermanos Angulo y por la campaña final por la independencia. Al combinarse con la guerra, ocasionó la respuesta política de los campesinos, quienes se involucraron en el conflicto y asumieron el ejercicio del poder.

Así, los campesinos de Huanta organizaron partidas de guerrillas para apoyar al ejército realista, que se hallaba comandado por oficiales que respaldaban las ideas liberales y las reformas constitucionales en la península (La Serna, Canterac, Valdés). Sus pares de Pampa Cangallo también formaron guerrillas, pero para apoyar a los insurgentes cusqueños (en 1814) o las expediciones libertadoras de San Martín y Bolívar (en 1820-1824). A partir de estas guerrillas, los campesinos de ambas localidades no solo movilizaron recursos y hombres para la guerra, sino que empezaron a demandar los derechos y la ciudadanía que la Constitución de 1812 prometía, o asumieron el poder en la estructura política que las mismas guerrillas armaron en la zona rural de Huamanga. En tal sentido, ambos grupos de campesinos utilizaron el liberalismo para estimular y legitimar el poder que adquirieron en medio de la guerra.

En este contexto, líderes campesinos de Huanta y Pampa Cangallo se transformaron en autoridades de comunidades y pueblos rurales y empezaron a gobernar en nombre del Estado republicano. Algunos transitaron de la colonia a la república y continuaron ejerciendo el poder en las siguientes décadas de la vida independiente; entonces, encajaron en nuestra estructura estatal republicana. Con ellos sucedió lo mismo que con los abogados criollos de Huamanga, quienes, al ejercer las 
funciones políticas y jurídicas que las Cortes y la Constitución de 1812 instituyeron en los Cabildos Constitucionales, transitaron con comodidad hacia las nuevas instituciones republicanas (Sala, 2012). Estos efectos, generados por el liberalismo doceañista, se sintieron tanto en la ciudad como en la zona rural de la intendencia de Huamanga.

Este liberalismo, que apareció en medio de la guerra, llegó para quedarse en el escenario regional. Constituyó la base del discurso con el que los campesinos de la región reclamaron la propiedad de sus tierras al Estado peruano en las siguientes décadas del siglo XIX. Sirvió, además, para que estos pobladores se conectasen con un Estado republicano que al menos les ofrecía la administración de la justicia. Pero esta es otra historia y tema de distinta investigación. 


\section{Referencias bibliográficas}

\section{Fuentes primarias}

Archivo Regional de Ayacucho (ARAy):

- Municipalidad: oficios varios sueltos; alcaldía: oficios remitidos.

- Intendencia: causas criminales.

- Juzgado de Primera Instancia: causas civiles.

- Corte Superior de Justicia: expedientes civiles de Huanta; expedientes civiles de Huamanga.

Comisión Nacional del Sesquicentenario de la Independencia del Perú (1971). Colección Documental dela Independencia del Perú. Acción patriótica del pueblo en la Emancipación. Guerrillas y montoneras. Tomo V, vol. 6. Lima: Lumen:

- Carta de Marcelo Granados a Francisco de Paula Otero, Huánuco a 8 de diciembre de 1820 (p. 481).

- Carta de A. J. De Sucre al ministro de la guerra, cuartel general de Huamanga a 15 de diciembre de 1824 (p. 131).

\section{Fuentes secundarias}

Annino, A. (2010). La ruralización de la política. En Annino, A. (ed.), La revolución novohispana, 1808-1821 (pp. 235-283). México D.F.: Fondo de Cultura Económica.

Bernabeú, S. (2010). Las Cortes de Cádiz y los indios: imágenes y contextos. En Ortega, M.; D. Levin \& M. E. Báez-Villaseñor (eds.), Los grupos nativos del septentrión novohispano ante la independencia de México, 1810-1847 (pp. 38-64). México D.F.-Mexicali B.C.: Universidad Autónoma Metropolitana-Unidad Iztapalapa-Universidad Autónoma de Baja California.

Bonilla, H. (1996). La oposición de los campesinos indios a la República peruana: Iquicha, 1827. Anuario Colombiano de Historia Social y de la Cultura, 23, 143-157.

Chiaramonti, G. (2005). A propósito del debate Herrera-Gálvez de 1849. Breves reflexiones sobre el sufragio de los indios analfabetos. En Aljovín, C. \& S. López (eds.), Historia de las elecciones en el Perú. Estudios sobre el gobierno representativo (pp. 325358). Lima: Instituto de Estudios Peruanos.

Huertas, L. (1972). Luchas sociales en Huamanga, 1700-1830. Tesis de doctorado en Historia, Universidad Nacional Mayor de San Marcos.

Huertas, L. (1982). Diezmos en Huamanga. Allpanchis, 17(20), 209-235.

Husson, P. (1992). De la guerra a la rebelión (Huanta, siglo XIX). Lima-Cusco: Instituto Francés de Estudios Andinos-Centro Bartolomé de las Casas. 
Igue, J. L. (2008). Bandolerismo, patriotismo y etnicidad poscolonial. Los morochucos de Cangallo, Ayacucho, en las guerras de la independencia, 1814-1824. Tesis de licenciatura en Historia, Pontificia Universidad Católica del Perú.

Jacobsen, N. \& N. Domínguez (2011). Juan Bustamante y los límites del liberalismo en el Altiplano: la rebelión de Huancané (1866-1868). Lima: SER.

McEvoy, C. (1997). La utopía republicana. Ideales y realidades en la formación de la cultura política peruana (1871-1919). Lima: Pontificia Universidad Católica del Perú.

Méndez, C. (2005). Tradiciones liberales en los andes o la ciudadanía por las armas. Campesinos y militares en la formación del Estado peruano. En Irurozqui, M. (ed.), La mirada esquiva. Reflexiones históricas sobre la interacción del Estado y la ciudadanía en los andes (Bolivia, Ecuador y Perú), siglo XIX (pp. 125-153). Madrid: Consejo Superior de Investigaciones Científicas.

Méndez, C. (2013). La guerra que no cesa: Guerras civiles, imaginario nacional y la formación del estado en el Perú. En Thibiaud, C., G. Entin, A. Gómez \& F. Morelli (eds.), L'Atlantique Révolutionnaire. Une perspective Ibéro-Américaine (pp. 379-420). Bécherel: Les Perséides.

Méndez, C. (2014). La república plebeya. Huanta y la formación del Estado peruano, 18201850. Lima: Instituto de Estudios Peruanos.

O’Phelan, S. (2007). Ciudadanía y etnicidad en las Cortes de Cádiz. En Aljovín, C. \& N. Jacobsen (eds.), Cultura política en los andes, 1750-1950 (pp. 267-290). Lima: Universidad Nacional Mayor de San Marcos-Instituto Francés de Estudios Andinos.

Pereyra, N. E. (2016). Los campesinos de Huamanga y la rebelión de 1814. En O'Phelan, S. (ed.), 1814: la Junta de Gobierno del Cuzco y el sur andino (pp. 339-362). Lima: Instituto Francés de Estudios Andinos-Pontificia Universidad Católica del Perú-Fundación M. J. Bustamante de la Fuente.

Pereyra,N.E.(2018). María Parado de Bellidoylaindependencia enla región deHuamanga: representaciones de una heroína popular. Revista Historia de las Mujeres, 20(181), 1-15. Consulta: 10 de marzo de 2021, https://www.cemhal.org/anteriores/2017 2018/181 Nelson.pdf

Pereyra, N. E. (2020). Campesinos republicanos. La sociedad rural de Ayacucho y el Estado peruano en el siglo XIX (1840-1880). Tesis de doctorado en Estudios Andinos, Pontificia Universidad Católica del Perú.

Pozo, M. J. (1968). Lo que hizo Huamanga por la independencia. Ayacucho: Imprenta González, 2da. Edición.

Quichua, D. (2019). La independencia en la región: Huamanga y la universidad de San Cristóbal, 1795-1824. Ayacucho: Universidad Nacional San Cristóbal de Huamanga.

Roca, J. S. (1866). Relación histórica de la primera campaña del general Arenales a la sierra del Perú en 1820. Buenos Aires: Imprenta de Mato.

Sala, N. (1996). Y se armó el tole tole. Tributo indígena y movimientos sociales en el virreinato del Perú, 1784-1814. Ayacucho: Instituto de Estudios Regionales José María Arguedas. 
Sala, N. (2001). Selva y andes. Ayacucho (1780-1829): historia de una región en la encrucijada. Madrid: Consejo Superior de Investigaciones Científicas.

Sala, N. (2011). El Trienio Liberal en el Virreinato peruano: los ayuntamientos constitucionales de Arequipa, Cusco y Huamanga, 1820-1894. Revista de Indias, 71 (253), 693-728.

Sala, N. (2012). Justicia conciliatoria durante el liberalismo hispano en el Perú: el caso de Huamanga. Anuario de Estudios Americanos, 69 (2), 423-450.

Trazegnies, F. (1987). La genealogía del derecho peruano: los juegos de trueques y préstamos. En Flores Galindo, A. (ed.), Pensamiento político peruano (pp. 99-134). Lima: Centro de Estudios y Promoción del Desarrollo.

Tilly, Ch. (1990). Coerción, capital y los Estados europeos, 900-1990. Madrid: Alianza.

Urrutia, J. (1994). La diversidad huamanguina: tres momentos en sus orígenes. Lima: Instituto de Estudios Peruanos, Documento de Trabajo N 57.

Vega, H. (1960). Cangallo y sus morochucos en la gesta emancipadora. Ayacucho: Imprenta González. 